\title{
Statistical studies of financial reports and stock markets
}

\author{
Shyam Sunder \\ Shyam Sunder
Yale School of Management, New Haven, Connecticut, USA
}

Statistical

\begin{abstract}
Purpose - The purpose of this paper is to examine the usefulness of statistical studies of financial reports and stock market data for improving corporate financial reports.

Design/methodology/approach - Analytical writing.

Findings - It is often claimed that statistical studies of co-variation between financial and stock market data can help set better financial reporting policy. Such co-variation, even when it can be estimated, tells us little about which financial reports help to make better financial decisions. A case in support of such claims remains to be made.

Practical implications - The readers are advised to be extremely careful in drawing inferences from studies of co-variation between accounting and stock market data for financial reporting policy.

Social implications - Inference from accounting empirical studies to policy needs better rationale to avoid bad policy consequences.

Originality/value - This paper raises original questions about policy inferences from a large class of empirical research in accounting.
\end{abstract}

Keywords Efficient markets, Financial reporting policy, Statistical co-variation

Paper type Research paper

It is possible to define better financial reporting in terms of the observable characteristics of the system, such as relevance, reliability, timeliness, etc. Such assessments, being dependent on context, are difficult to generalize; and it seems more attractive to assess financial reporting regimes on the basis of their observable consequences. Market phenomena being more readily observable than individual and organizational behavior, this line of reasoning leads one to the goal of financial reporting for better markets.

Financial reporting serves many constituencies, including markets for financial capital, labor, and products and services. There has been a strong but largely unexplained inclination to focus attention on markets for financial capital, leaving the other two classes of markets largely out of the accounting discourse. Even within the class of capital markets, most of the attention has been given to markets for common equity of publicly traded corporations.

This paper examines the inferences we may or may not be able to draw from statistical studies of financial reports and secondary markets for equity of public firms. The focus on equity markets should not be taken to suggest that the role of financial reports in other markets is unimportant. Nor does it imply that "better markets," however defined, necessarily lead to higher welfare or a better society. Important as these questions are, they are outside the limited scope of this paper.

\section{JEL Classification - M41}

(C) Shyam Sunder. Published in Journal of Capital Markets Studies. Published by Emerald Publishing Limited. This article is published under the Creative Commons Attribution (CC BY 4.0) licence. Anyone may reproduce, distribute, translate and create derivative works of this article (for both commercial \& non-commercial purposes), subject to full attribution to the original publication and authors. The full terms of this licence may be seen at http://creativecommons.org/licenses/by/4.0/legalcode

An earlier version of this paper was presented at a symposium in honor of K.R. Balachandran.

Received 17 July 2017 Accepted 17 July 2017 
JCMS

1,1

\section{Better markets for common equity}

It is useful to have a shared view of what we regard as better markets for common equity. Once we have mapped the linkages between alternative financial reporting regimes and the characteristics of equity markets, we may have the chance to improve markets by selecting financial reporting regime(s). The concepts of perfect and complete markets in economics suggest a promising starting point. A market is regarded as being perfect if (among other things) (1) all participants have the relevant information, (2) no participant has the power to influence the prices, (3) the cost of entering and exiting the market is zero, and (4) all participants have access to the relevant production technology. A market is complete if all possible resources, and state-contingent claims on them, are traded readily.

Perfect and complete markets are the idealized and simplified economic models of a complex world. Whether or not we can alter a market to be more perfect and complete, and whether or not such alteration is desirable, are difficult questions. When the mechanism to intervene in the market, with its own imperfections, is included in analysis, the results of such intervention are not necessarily closer to the goal of perfection. The desirability of intervention depends on the point of view selected for analysis, because few interventions can bring about Pareto improvements in the status quo.

The information condition for market perfection (mentioned as Item 1 above) gives rise to the possibility of a linkage between financial reporting and market results. However, financial markets operate in an environment of uncertainty, where perfection is not achievable, and the ideal is shifted from perfect to efficient markets. Informationally - efficient markets are defined as those in which prices incorporate the aggregation of all information in possession of the market participants. In other words, prices in efficient markets are the same as they would be had every participant possessed the aggregation of all the information possessed by each of its individual participants. As Hayek (1945) pointed out, markets function as aggregators of bits and pieces of information in possession of the participants.

The market's aggregation property, to the extent it is valid, tells us little about which pieces of information should be in the hands of which traders, and when traders should have the information for markets to be more efficient. Since much of the information about business concerns uncertain events of the future beyond anyone's knowledge, making "all information" available to all the traders is not possible. Of the limited amount of information possessed by corporate managers, making it all available to the public has proprietary, regulatory, and competitive implications. Further, it is not clear what mechanism(s) can be used to induce managers to disclose information when they do not think that disclosure will serve their own personal interests.

Statistical analyses of linkages between financial reports and stock market data have sought to guide financial reporting policy. The argument is vaguely appealing: stock markets are efficient in the sense of reflecting all relevant information in the prices; we can therefore use guidance from stock markets to identify which information (and which information-generating accounting methods) markets find relevant to determination of prices; this can be achieved by identifying the accounting methods which produce data with greater statistical proximity (e.g. higher product moment or rank correlation) with stock prices; and such methods of accounting can be used to promote market efficiency. Since ideal markets in the presence of uncertainty are efficient, this method of arriving at accounting policy will promote market efficiency, and thus "better markets." Each of these four arguments calls for some scrutiny.

\section{Stock markets are efficient}

What is the sense in which stock markets can be regarded as efficient, and what are the implications of the various available interpretations for financial reporting policy? 
Interpretations range from "the price is right" to more or less tautological statements about efficiency (e.g. price is a function of the information system associated with the market, and each information system generates its own "efficient" market price). Under the first interpretation, price, being independent of the information system, becomes irrelevant to the determination of financial reporting policy. Under the second interpretation, the choice of reporting policy requires choosing among the multiple efficient equilibria (see Kanodia, 1980 on multiple efficient equilibria and Sunder, 1989 on the problems of using event studies from efficient markets to guide accounting policy).

\section{Using accounting methods relevant to the determination of prices}

This is a commonsense argument. The problem is, that under the first interpretation of efficiency, accounting methods do not matter. Under the second interpretation, all accounting methods (excluding trivial equivalents) are relevant.

\section{Statistical proximity (e.g. correlation) as identifying criterion}

If we use statistical proximity between accounting and stock market variables as the criterion for choosing among accounting alternatives, achieving greater proximity, indeed identity, is trivially simple: by using market variables as the basis of accounting. For example, if income were measured as the change in market capitalization of equity (adjusted for capital transactions and dividend payments), the accounting measures would be identical to market measures. Yet such a system, with perfect proximity between accounting and market variables, will provide no information to the market participants to assist them in making their investment decisions.

\section{Such accounting methods promote efficient ("better") markets}

As mentioned above, accounting methods chosen on the basis of greater statistical proximity between accounting and stock market variables provide no assurance that they will help make the markets more efficient or better in some specified respect.

It has been popular to suggest that one should choose financial reporting practices on the basis of statistical co-variation between accounting and stock market data. I used this approach in my thesis (Sunder, 1973, 1975), and found it to be problematic. Yet, here is a quote from a recent paper:

This paper aims at determining the value relevance of financial reporting. [...] This study aims at explaining likely impact of financial reporting by listed companies on the market prices of their shares. Our study reveals that the value relevance of published financial statements, per se, is negligible. [...] The results of our investigation depict negligible value being added by cash-flow reporting (Vishnani and Shah, 2008, p. 84).

There are two problems with the argument. I shall not address the first: could the stock market be the sole or dominant basis for choosing corporate financial reporting? Rather, I focus on the second: does statistical co-variation between accounting and stock market data deliver on its promise of helping us choose better methods of financial reporting?

Consider the basic structure of the large body of research studies based on the premise that the criterion of statistical co-variation between accounting and stock market data can help us choose better financial reporting methods. The status quo Financial Reporting System A presumably causes Price System A, the causal direction being inherent in the search for information for better markets.

$$
\text { Financial Reporting System A } \quad \rightarrow \quad \text { Price System A }
$$


JCMS

1,1

Once we have data on both sides of this arrow, we can plug that data into estimation algorithms on a computer and estimate $\mathrm{R}(\mathrm{A})$, where $\mathrm{R}(\mathrm{A})$ is the co-variation of accounting data on the left and prices on the right.

Financial Reporting System A $\underset{R(A)}{\rightarrow}$ Price System A

8

Suppose a policymaker is considering a hypothetical alternative, Financial Reporting System B. Presumably, Financial Reporting System B will cause Price System B to be generated.

Financial Reporting System B $\rightarrow$ Price System B

It is conceivable that we could find some way of estimating what the accounting numbers will be under $B$, and then we would like to do a co-variation estimate, $R(B)$, which is the relationship between the stock prices under $\mathrm{B}$ and accounting data under $\mathrm{B}$.

$$
\text { Financial Reporting System B } \underset{\mathrm{R}(\mathrm{B})}{\rightarrow} \text { Price System B }
$$

What can we learn about the relative desirability of Method A vs Method B by comparing the co-variation of each method with the respective stock prices they generate $-R(A)$ and $R$ (B)? Suppose that the statistical proximity of accounting numbers to stock prices is to be the criterion to be maximized. As mentioned earlier, it is trivial to achieve this accounting nirvana; all one has to do is to report the change in market capitalization of the firm as income, close the accounting department, and achieve a perfect "information" system. However, it would be accounting from the markets and not accounting for the markets.

But things are much worse than the failure of co-variation to guide us to better systems of reporting; in many cases, the co-variation $\mathrm{R}(\mathrm{B})$ itself cannot be estimated. One might be able to estimate the accounting data under B which has not yet been implemented. Furthermore, one does not have the stock price data under the hypothetical financial reporting regime $B$, and therefore, one has no way of even estimating $R(B)$ so it can be compared to $\mathrm{R}(\mathrm{A})$.

Financial Reporting System A $\underset{R(A)}{\rightarrow}$ Price System A
Financial Reporting System B $\underset{R(B)}{\rightarrow}$ ? Price System B

What can one do without data on Price System B? Here's a trick, or sleight of hand - estimate the co-variation $R^{*}(B)$ of Financial Reporting System B with Price System A (Figure 1).

The published study of Vishnani and Shah (2008), as well as many other accounting studies, followed this route. What does the comparison of $\mathrm{R}(\mathrm{A})$ with $\mathrm{R}^{*}(\mathrm{~B})$ tell us? It cannot tell us whether B is better or worse than A. In fact, their comparison is quite irrelevant, unless one believes that Price System B is the same as Price System A. Even then, a change

Figure 1.

Dealing with the absence of $\mathrm{P}(\mathrm{B})$ by a sleight of hand

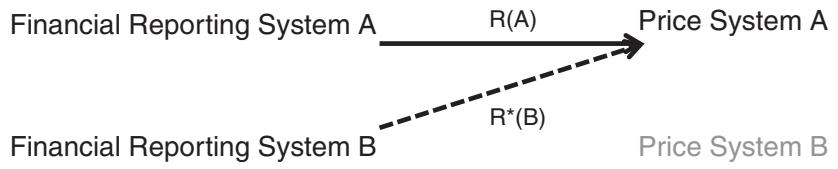


of accounting makes no difference to the price system. If accounting makes no difference to stock prices, why choose accounting on the basis of stock prices?

In summary, it is hard enough to derive the logical inference from the comparison of $R(A)$ and $\mathrm{R}(\mathrm{B})$. The comparison of $\mathrm{R}(\mathrm{A})$ to $\mathrm{R}^{*}(\mathrm{~B})$, which is the norm in a significant part of accounting literature, is not relevant to policy. Accordingly, the case for using the results of these popular studies of co-variation between accounting and stock market data for the purpose of setting financial reporting policy remains to be made.

Statistical studies of financial reports

\title{
References
}

Hayek, F.A. (1945), "The use of knowledge in society", American Economic Review, Vol. 35 No. 4, pp. 519-530.

Kanodia, C.S. (1980), "Effects of shareholder information on corporate decisions and capital market equilibrium”, Econometrica, Vol. 48 No. 4, pp. 923-953.

Sunder, S. (1973), "Relationship between accounting changes and stock prices: problems of measurement and some empirical evidence", Empirical Studies in Accounting: Selected Studies (Supplement), Journal of Accounting Research, Vol. 11, pp. 1-45.

Sunder, S. (1975), "Stock price and risk related to accounting changes in inventory evaluation", The Accounting Review, Vol. 50 No. 2, pp. 305-315.

Sunder, S. (1989), "Proof that in an efficient market, event studies can provide no systematic guidance to making of accounting standards and disclosure policy", Contemporary Accounting Research, Vol. 5 No. 2, pp. $452-460$.

Vishnani, S. and Shah, B.K. (2008), "Value relevance of published financial statements, with special emphasis on impact of cash flow reporting", International Research Journal of Finance and Economics, Vol. 17, pp. 84-90, available at: www.eurojournals.com/Pages $\% 20$ from $\% 20$ irjfe17sushma.pdf

\begin{abstract}
About the author
Shyam Sunder is the James L. Frank Professor of Accounting, Economics and Finance at Yale School of Management. His research on financial markets and macroeconomics has appeared in over 200 articles in prestigious accounting, economics and finance journals. His inquiry (with D. Gode) into structural properties of markets using zero- or minimally intelligent agents was a seminal innovation whose applications have spread to computer science, engineering, finance, artificial intelligence, e-commerce, and other disciplines. His tenth book, Risky Curves: On the Empirical Failure of Expected Utility, co-authored with Dan Friedman, Mark Isaac, and Duncan James, appeared in 2014. Shyam Sunder can be contacted at: shyam.sunder@yale.edu; http:/faculty.som.yale.edu/shyamsunder/
\end{abstract}

For instructions on how to order reprints of this article, please visit our website:

www.emeraldgrouppublishing.com/licensing/reprints.htm

Or contact us for further details: permissions@emeraldinsight.com 